\title{
Personal-Organization Matching Literature Review
}

\author{
Ying Wang ${ }^{a}$, Xin Zhu ${ }^{\text {b }}$ \\ School of Management, Guangxi University of Science and Technology, Liuzhou 545000, China. \\ a1649707973@qq.com, b5266736@qq.com
}

Keywords: Personal-organization matching, concept definition, structure measurement, influence effect.

\begin{abstract}
Personal-organization matching refers to the compatibility of individual characteristics and organizational characteristics, which has a positive impact on individual work attitude and work behavior. On the basis of literature research, this paper sorts out the domestic and foreign personal-organization matching theory and related research from the aspects of the concept connotation, structure and measurement, impact effect of personal-organization matching. Analyze the problems in personal-organization matching research and look forward to future research directions.
\end{abstract}

\section{Introduction}

With the rapid development of the social economy and the advancement of the global economic integration process, the competition among enterprises has become increasingly fierce. Under frequent changes in the environment and strong competitive pressures, companies have to face frequent internal changes and personnel changes. At this time, how companies obtain good employees, make them reasonably equipped and to exert their full potential, become enterprises to win the living space and The key to future development. As the core research topic of organizational management research, personal-organization matching has received the attention of both the theoretical and practical circles because of its unique role in the company's acquisition of suitable talents, giving full play to its advantages, and ultimately enhancing its competitiveness. It is considered as an important human resource management measure for organizations to gain competitive advantage. Numerous studies have also shown that good personal-organization matching is an important source for companies to attract, recruit and retain talented people, improve organizational effectiveness, and help companies obtain sustainable competitive advantages. This article plans to introduce the theory of personal-organization matching and the new progress of related research on the basis of relevant research at home and abroad.

\section{The Concept of Personal-Organization Matching}

The personal-organization match comes from the personal-environment matching theory, which is based on the psychological field theory first proposed by Lewin (1951) [1]. The theory holds that individual behavior is a function of the interaction between the individual and the environment, not just individual trait factors or environmental factors. Personal-organization matching can be understood in a broad sense as a state of fit and adaptation between the individual and the organizational environment. For the concept connotation of personal-organization matching, different scholars have different opinions, which are mainly divided into three categories: single-dimension, two-dimension and three-dimension.

\subsection{Single Dimension: Conformance Matching.}

Chatman (1989) believes that the match between individuals and organizations is highly consistent and consistent between people and organizations in terms of norms and values[2]. Holland's theory of "matching of personality traits with work environment” is typical Theory [3], Schneider's attract-select-friction model (abbreviated as ASA model) also emphasizes that personal goals and values are consistent with organizational goals and values [4]. The ASA model believes 
that people are attracted by organizations that are similar to their own personality traits. They enter the organization through self-selection and organizational selection, and then undergo socialization of the organization, resulting in retention or departure. Holland's theory of "matching personality traits with work environment" promotes the development of personal and environmental matching theory and enriches the research perspective. The ASA model provides an explanation for the formation mechanism of personal and organizational matching.

\subsection{Two Dimensions: Conformance Matching and Complementary Matching.}

Muchinsky \& Monahan (1987) defined personal-organization matching from two aspects of consistency matching and complementary matching. Consistency matching focuses on the similarities between individuals and organizations, for example, they share the same values, attitudes and goals; complementary Matching refers to the mutually satisfying relationship between individuals and organizations. One party provides the other party's needs, and the specific performance is that the individual's characteristics meet the needs of the organization [5].

Cable \& Judge (1997) defines personal-organization matching from the perspective of supply and demand and mutual satisfaction, and divides them into demand-supply matching and requirement-capacity matching [6]. Among them, demand-supply matching is defined from the point of view that the individual is satisfied by the organization. When the resources and conditions provided by the organization are required and cherished by the individual, matching occurs. Requirements-capacity matching is from the perspective of the individual being satisfied by the organization. Defining matching, personal-organization matching occurs when individual knowledge, skills, and other resources meet the organization's requirements.

\subsection{Three Dimensions: Conformance Matching, Capability-Requirement Matching, Demand-Supply Matching.}

Kristof (1996) proposed a three-dimensional model of personal-organization matching. The three dimensions are consistency matching, demand-supply matching, and requirement-capacity matching. Among them, demand-supply matching and requirement-capacity matching constitute complementary matching [7]. Conformance matching refers to the similarity between individual and organizational characteristics. Individual characteristics include the individual's attitude, values, and personality. Organizational characteristics include the organization's values, core concepts, organizational climate, and goals. When individuals and organizations have similar characteristics, individuals and organizations have potential consistency. Demand-supply matching means that individuals' motivations and needs match the resources provided by the environment to satisfy individual motivations. Requirements-capability matching is the definition of matching from the perspective of individual ability to meet organizational requirements. Matching in this respect emphasizes the individual's consumption of knowledge, skills, time, and energy in order to meet the requirements of the proposed task.

\section{Personal-Organization Matching Measurements}

The personal-organization matching measurement method is mainly divided into direct measurement and indirect measurement. Direct measurement refers to the measurement of an individual's perception or subjectively perceived match by direct questioning. The direct measurement is concerned with the individual-perceived match. Whether or not the individual and the organization have objective similarities or meet reciprocal demand objectively, the match is established once the individual perceives matches with the organization. However, since the basis of direct measurement is the subjective perception evaluation of individuals and the personal color is strong, some scholars have criticized this method. For example, Edwards (2010) believes that direct measurement will prompt individuals to confuse the characteristics of their environment with the environment, thus hindering their independent role[8]; also, scholars point out that direct measurement adopts the self-reporting measurement method and matching. The results of the evaluation and other relevant variables are from the same subject and may have high social appraisal during the evaluation process. This kind of homogenous data with social compel ability may make the 
study possible with serious common method deviations. The problem is that a large number of variability results have a serious impact on the measured results, making the research results ineffective.

The indirect measurement method is a method of making measurements by comparing individual characteristics and tissue characteristics separately, and then comparing the differences between the two. Long Lirong and Zhao Huijuan (2009) divide the measurement index into two categories: difference score index and correlation coefficient index [9]. The difference score index includes three kinds of reduction, absolute value, and square difference. It is assumed that the smaller the difference, the better the consistency between employees and organizations. The coefficient of correlation index assumes that the higher the correlation coefficient between employee and organizational characteristics, the better the match. This measurement method is used to actually evaluate the similarities and complementary between people and organizations. It is therefore considered to reflect the actual match between people and organizations and to better measure the true match between people and organizations.

\section{Research on the Effect of Personal-Organization Matching}

The personal-organization matching theory stems from the perspective of interactive psychology: that personal characteristics and contextual characteristics combine to influence the response of a specific individual to a given situation, and there is little research on the antecedent variables of personal-organization matching. Most of the studies explored their impact on outcome variables, mainly in two areas of research: human resource management and organizational behavior. In terms of organizational behavior, scholars mainly discuss the relationship between personal-organization matching and individual work attitude and work behavior variables (such as job satisfaction, organizational commitment, organizational citizenship behavior, turnover intention, turnover rate, etc.); In terms of resource management, it mainly discusses the practice and application of personal and organizational matching theory in employee recruitment, training, and employee development.

\subsection{Research on Organizational Behavior.}

The relationship between personal-organization matching and employee work attitude is a common focus of scholars. A large number of empirical studies have shown that personal-organization matching can predict the attitude of employees. Westerman \& Cyr (2004) uses the consistency of values to evaluate individual-organization matching and finds that matching results can affect employee job satisfaction [10]. In addition to job satisfaction, scholars also conducted research on organizational commitments and turnover tendencies. Lauver \& Kristof (2001) believe that those employees who differ significantly from the organizational values may leave the organization due to strong inadequacies [11]. Xu Yufeng, Wang Qun et al. (2015) also demonstrated in their research that personal-organization matching has a predictive effect on organizational commitment and turnover intention [12].

There is also a certain correlation between personal-organization matching and organizational members' work behaviors and job performance. Verquer et al. (2003) found that personal-organization matching has a significant impact on employees' job performance, in terms of pursuing sense of achievement and organizational atmosphere. Conformed employee work performance is higher than that of employees who deviate from the organizational atmosphere [13]. At the same time, a high degree of personal-organization match leads to more frequent organizational citizenship behavior. Yaniv et al. (2010) found that consistent matching of values can promote employees to generate more organizational citizenship behavior [14]. Yan Yuqin (2013) conducted an empirical study of individual's help behaviors and suggestions, and he believed that personal-organization matching has a significant positive effect on both behaviors [15].

\subsection{Research on Human Resource Management.}

Research on the application of personal and organizational matching mainly focuses on two major areas of employee recruitment and training. In employee recruitment, Piasentin \& Chapman (2006) believes that the personal-organization matching model facilitates the organization to make correct 
personnel selection decisions [16]. Using the matching model, the organization can recruit newcomers with similarities to existing organization members. Employees are hired rather than the best. Through research, it has been found that in the actual interview process, the interviewer perceives (but not actually) the matching situation has a greater impact on the employment decision. In addition, personal and organizational matching also plays an important role in employee training. Organizations train employees in various ways to enable individuals to learn various aspects of the organization's environment and to psychologically recognize the organization's goals and values in order to achieve a better match between employees and organizations and to bring higher work to the organization. Satisfaction, organizational commitment and lower turnover.

\section{Research Deficiency and Research Prospect}

\subsection{From Static Matching Research to Dynamic Matching Research.}

It is not difficult to see that past research scholars have provided many effective methods and ideas for our research from the domestic and foreign methods and models of personal and organizational matching research. However, they also have limitations and deficiencies in their research. For example, most researchers and managers start from a static point of view. They rarely consider the concept of dynamic matching; they lack the means for dynamic evaluation and measurement and urgently need to wait for research and development.

In the future human resources management, we should consider dynamic matching more because the employees and organizational environment are constantly changing, and the differences between the two are also evolving. Therefore, we should combine organizational situations, especially the organization of employees. The socialization process started a longitudinal study.

\subsection{Study on the Homogeneity Consequences of Personal-Organization Matching.}

An important result of personal-organization matching is the relative homogeneity of the organization. Organization homogeneity may be an advantage in the early stages of organizational development, because homogeneity will increase cooperation and communication among employees and enhance the cohesion and activity efficiency of the organization. However, since this homogenous cycle is essentially a kind of inbreeding, the development to the late stage of the organization may lead to the organization's rigidity and lack of innovation, as well as reducing the adaptability to changes in the external environment. Therefore, the consequences of the homogenization of individual-organization matching will also be important topics for our research.

\section{References}

[1]. Lewis K. Field theory in social science: selected theoretical papers [M]. London: green wood press publisher, 1952:1-60.

[2]. Chatman J. A. Improving interactional organizational research: a model of person-organization fit [J].Academy of Management Review, 1989, 14(3):333-349.

[3]. Holland J. L. Making vocational choices: A theory of careers [M]. Englewood Cliffs, NJ: Prentice-Hall, 1973.

[4]. Schneider B, Goldstein, H. W. \& Smith D. B. The ASA framework: An update Personnel Psychology, 1995, 48, 747-773.

[5]. Muchinsky P. M, Monahan C. J. What is person-environment congruence Supplementary versus complementary models of fit [J].Journal of Vocational Behaviour, 1987, 31(3): 268-277?

[6]. Cable D. M, Judge T A. Interviewer's perceptions of person-organization fit and organizational selection decisions [J]. Journal of Applied Psychology, 1997, 82(4): 546-561.

[7]. Kristofer A. L. Peron-organization fit: An integrative review of its conceptualizations measurement, and implications. Personnel Psychology, 1996, 49: 1-30. 
[8]. Edwards J. A, Bills berry J. Testing a multidimensional theory of person-environment fit[J].Journal of Managerial Issues,2010,4: 476-493.

[9]. Laron Long, Huijuan Zhao. Research on Personal-Organization Values Matching: The Advantage Effect of Performance and Social Responsibility [J]. Chinese Journal of Management, 2009, 6(06):767-775.

[10]. Waterman J.A, Cyr L.A. An Integrative Analysis of Person-Organization Fit Theories [J].International Journal of Selection and Assessment, 2004, 12(3): 252-261.

[11]. Louver K. J, Kristofer-Brown A. Distinguishing between employee's perceptions of person-job and person-organization fit, Journal of Vocational Behaviour, 2001, 59: 454-457.

[12]. Yuen Xu, Qu Wang, Hue Li, Lin Chen. Study model construction of the relationship between personal-organization matching, job burnout and turnover intention [J]. Journal of Leadership Science, 2015, (20):48-50.

[13]. Jerquer M. L, Behr T. A, Wagner, S. H. A meta-analysis of relations between person-organization fit and work attitudes [J]. Journal of Vocational Behaviour, 2003, 63(3):473-489.

[14]. Yana E, Lava O. S, Site G. Person-Organization Fit and Its Impact on Organizational Citizenship Behaviour as Related to Social Performance [J]. Journal of General Management, 2010, 36(2): 81-89.

[15]. Yun Yan, Change Dai, Huizhou Yang. Human-organization matching, job satisfaction and role-oriented behaviour [J]. Soft Science, 2013, 27(5):96-100.

[16]. Piasentin, K. A, Chapman. Subjective person-organization fit: Bridging the gap between conceptualization and measurement [J]. Journal of Vocational Behavior, 2006, 69:202-221. 